DOI: $10.15503 /$ jecs20141-201-205

Journal of Education Culture and Society No. 1_2014 201

\title{
DIGITAL CULTURE AND SOCIAL MEDIA VERSUS THE TRADITIONAL EDUCATION
}

\author{
AGIM POSHKA \\ Faculty of Languages, Cultures and Communications, \\ The South East European University, \\ Address: Ilindenska bb, Tetovo Macedonia (FYROM) \\ a.poshka@seeu.edu.mk
}

\begin{abstract}
This article aims to reflect on the increasing momentum that social media have in the everyday life our students and to investigate the uniqueness that this media offers to the process of education. The study investigates the benefits that Facebook and Twitter have as the leading technologically mediated spaces and its application to the learning habitat of the learner in the public pedagogy. The article reflects on the opportunities that social media offers in order to avoid the self-created intellectual chamber by allowing educators to share and challenge ideas and concepts through the so called non-traditional "great spare time revolution".
\end{abstract}

Key words: Digital Culture, Social media, public pedagogy, Facebook, Twitter, non-traditional methodology

\section{INTRODUCTION}

The pedagogical reality in our classrooms has dramatically changed since the Grammar Translation method but constructivists today may also argue that constructing a learning reality is impracticable without the presence of technology and the vices inheriting it. At this stage the pedagogy should be way beyond the paradigm that technology is important in class but reflect on the ways that public technology such as social media affect the learning process. It is clear that Facebook, Twitter and similar media are now present more than ever in the daily habitus of the $21^{\text {st }}$ century learner. The yearly report on the usage and popularity of Facebook released in December 31, 2013 (zeforia.com/social media infografics) states that in Europe, over 223 million people are on Facebook. The success of this corporation might seem as a remarkable success in income however for us as educators it would be another opportunity to face this new Facebook age regardless of our age or pedagogical views. Obviously the reality is quite different from the time when we graduated and keeping up is more than a must.

With the appearance of internet and later-on the Smartphone technology our students are distracted than at any time in the history of education. You are trying to impress with your marker in the white board, by using your voice, although 
your students have in their hands or pockets every possible piece of information needed. Among other reasons why teachers were quite respected few decades earlier was also that teacher was the one of the most important source of information. Unfortunately this is not the case today. Often our students have access to more information than we do. This does not minimize in any way the role of the educator but raises the bar regarding the methodology we ought to use in order to get their attention and hopefully inspire them.

Going back to my first argument it seems that it's quite important to use all this available technology and media and develop what Henry A. Giroux (1996) calls a public pedagogy. According to his concept we use the term and concept of public pedagogy to refer to the informal learning and educational experiences occurring within popular culture, popular media, and everyday life that teach youth through the ways in which they represent people and issues and the sorts of discourses they produce and disseminate (Richard L. Freishtat \& Jennifer A. Sandlin,2009, p. 504).

\section{IS FACEBOOK BECOMING IMPORTANT TO EDUCATORS?}

We are aware as educators that the best time to accelerate learning is when students attention is at peak, or similar to the proverb of Sir James Dewar "minds are like parachutes they only function when they are open". The fact that they voluntarily access this media is a category of positive state of mind that students have by wanting to socialize and get informed. This is a moment when our goals can be absorbed more naturally. The process might be more natural and similar to the state of mind of first language acquisition in which the learning is acquired naturally since the cognition process progression is at the anxiety-free setting.

Another important element to be considered is the timing. Based on the abovementioned social media report $50 \%$ of $18-24$ year-olds go on Facebook when they wake up (www.theSocialSkinny.com). This would be a time gap opportunity that needs to get considerable consideration particularly the fact on the variable timing that this social media offers has access in student's everyday life. The frequency and the dynamic of this and similar social media have been investigated by a number of educators in order to measure or evidence the possible presence of the public pedagogy. There are a number of studies conveyed lately (besides the impact of radio, TV and movies) that examine the practices of the so called technologically mediated spaces including a number of interactive applications such as video games, Smart Phone applications, free SMS applications etc and one media that had an enormous popularity is Facebook. According to Facebook.com, there are over 1.19 billion active Facebook users. This is an 18 percent increase year on year. For us as educators it is quite clear that Facebook is extensive in size, information and usage, and instead of taking no notice of we have to consider it as a new exploratory tool in our classes. One pedagogical goal would be to consider it as a new common ground for educational interaction among us and our students. As every phenomenon social media has its limitations too. Since this medium is relatively new, there has been very little research regarding it its educational practicality. Also there is very little evidence that the technologically mediated spaces can serve for educational research purpo- 
ses. Stuart Hall (1996) states that studying the public pedagogy of technologically mediated spaces where youth engage within a context of globalization and emerging technologies works to deconstruct how meanings are produced "in specific historical and institutional sites within specific discursive formations and practices, by specific enunciative strategies" (Freishtat \& Sandlin, 2009, p. 505). Richard L. Freishtat \& Jennifer A. Sandlin(2009), also state that despite the growing popularity and incorporation into youths' daily lives of technologically mediated spaces, ideas regarding their public pedagogy are seldom taken up as part of a bigger attempt to explain how learning takes place outside of schools or what it means to assess the political significance of understanding the broader educational force of culture in the new age of media technology, multimedia, and computer-based information and communication networks (Giroux, 1996).

\section{IS TWITTER A FACTOR IN CREATING NETWORKS AND NON-TRADITIONAL PROFESSIONAL DEVELOPMENT?}

A key element in most of the methodological philosophies was the need for a group work, peer correction or other modes of cooperation in the learning process. This feature is also seen as a bridge from teacher-centered to a more student centered approach. This kind of behavior opens floor to the exploration of more cooperation tasks in the learning process instead of competition. Accidentally or not, the social media has created cooperation through communication in the center of activity as a main element of the social media which leads to natural networking opportunities. Although often we create this preconceived notion that networking is important to our students, social media is not necessarily only important for students but also for teachers in creating networks, contacts and opportunities for professional development. A social media that seems to have strong impact in networking by the follow option is Twitter. A teacher named Nicholas Provenzano opened a Twitter account in January 2010 and now has 30,000 followers. Provenzano stated that "he had a simple goal when he started Tweeting and blogging: He wanted to share what he knew about his classroom with the world.. but in return, the world has shared what it knows with him"(William Ferriter \& Nicholas Provenzano, 2012). What seems to be advantage with this type of media is the networking with fellow professionals and the opportunity to reflect, measure, launch and share professional beliefs and values that are central for professional development.

\section{THE UNCONVENTIONAL AND THE NONTRADITIONAL IN THIS TYPE OF MEDIA}

Although in the previous examples we mentioned a number of advantages that specific social media has if applied in the process of education there are a number of factors that make this type of tools more attractive in comparison to the traditional teaching tools and norms. Among them two factors that seemed to be central in the process is the accessibility to these tools and the timing that expanded considerably the conventional modes in education. 
The abovementioned factors gained a clear support also from the technological developments of smart-phones, I-pads and other similar gadgets that made the accessibility more practical and approachable. William Ferriter \& Nicholas Provenzano,(2012) state that the answer is that innovation happens when minds come together in order to share ideas. Traditionally, that sharing required people to be in the same place at the same time. Today, sharing ideas can happen anytime, anywhere. Whether they are poking through Twitter streams on Smartphone's before the morning bell rings, reading blog entries on iPads while sitting in waiting rooms, or extending conversations started on e-conferences on laptops while unwinding after a long day of work, digitally connected teachers are tapping into what Clay Shirky and Dan Pink (2010) call "the great spare time revolution".

If followed carefully the labeling that traditional media used to describe these networking phenomena developed as follows. The growing popularity of the social networking moved from a basic website promoting socializing opportunities to a number of sites with similar goals that were later labeled as social mediums and lately more and more in literature we find this phenomenon labeled as socially mediated spaces. Here is a visual figure of these developments: Social sites

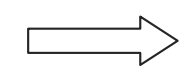

social media

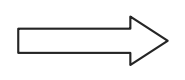

technologically mediated spaces

Fig.1 Social Media development.

Source: Poshka, A. (2014).

Another element that could be considered an advantage of this type of media is the possibility in creating opportunities to avoid what W.Ferriter and N.Provenzano (2012) calls the self-created intellectual chamber in which educators are sometimes consciously or unconsciously are trapped in. This type of media allows exchange of educational ideas and concepts that should be considered as benefits of the technologically mediated spaces.

\section{CONCLUSION}

Social media is clearly quite big to be ignore and finding ways in incorporating it in class makes our classes more attractive and esthetically more approachable. By esthetically I mean creating a learning setting that is similar to stage performance which allows students to enjoy the class development through using their favorite gadgets as variety of learning. We cannot alienate the learning process by prohibiting their life companion gadgets. Although this might seem as unconventional and not loyal to the learning practices it is important for us to be loyal to the learning process and not the learning tools.

This type of media is slowly becoming significant to the teachers community as well and it helps in achieving these goals:

- Networking opportunities for the teaching community.

- Promote cooperation versus competition in the teaching profession.

- Possibilities for professional developments. 
- Create opportunities to avoid the self-created intellectual chamber but allow to share and challenge ideas and concepts in education.

Social media is increasing its popularity and application and is becoming a reality although virtual platforms manage their development. It is important that this new reality has its space in the educational process and be considered not only as a social and networking space but a medium that helps in increasing values on and about education.

\section{REFERENCES}

Freishtat, R.L., \& Sandlin,J,A. (2010). Shaping Youth Discourse About Technology: Technological Colonization, Manifest Destiny, and the Frontier Myth in Facebook's Public Pedagogy. Educational Studies: Journal of the American Educational Studies Association, 46: 503-523

Ferriter, M., \& Provenzano,N. (2013). Young educators are replacing professional development sessions and conferences with Twitter, blogs, and Edcamps as their preferred ways to learn and share new ideas. Retrieved from: www.kappanmagazin.org.

Shirky, C., \& Pink,D.(2010). Cognitive Surplus: The Great Spare-Time Revolution. Retrieved May24,2010 from: http://www.wired.com/magazine/2010/05/ff_pink_shirky/.

Provenzano, N. (2012). Where I am and how I got here. Retrieved (May 25, 2012) from: www.thenerdyteacher.com/2012/05/where-i-am-and-how-i-got-here.html.

Giroux, H.A., (1996). Is There a Place for Cultural Studies in Colleges of Education? H.A. Giroux, C. Lankshear, P.McLaren, \& M. Peters (Eds.), Counter narratives: Cultural Studies and Critical Pedagogies in Postmodern Spaces (pp. 41-58). New York: Routledge.

Johnson, S. (2010). Where good ideas come from: The natural history of innovation. New York: Riverhead Books.

The Top 20 Valuable Facebook Statistics. Retrieved February 19, 2014 from: http://zephoria.com/ social-media/top-15-valuable-facebook-statistics/.

Joosten,T. (2012). Social Media for Educators: Strategies and Best Practices. San Francisco: Jossey Bass Higher and Adult education series.

Dixon,B,J.(2012). Social Media for School Leaders: A Comprehensive Guide to Getting the Most Out of Facebook, Twitter, and Other Essential Web Tools. San Francisco: Jossey Bass Higher and Adult education series.

Poshka, A. (2014). Evaluation of the Cultural Element. Tetovo, Macedonia: Office for Research - South East European University. Macedonia.

Hall, Stuart. (1996). “Who Needs Identity?" Questions of Cultural Identity. Edited by Stuart Hall and Paul du Gay. Thousand Oaks, CA: Sage. 